\title{
On the Application of 3D X-Ray Microtomography for Studies in the Field of Iron Ore Sintering Technology
}

\author{
Volodymyr Shatokha ${ }^{1}$, Iurii Korobeynikov ${ }^{1}$ and Eric Maire ${ }^{2}$ \\ ${ }^{1}$ National Metallurgical Academy of Ukraine \\ 2Université de Lyon, INSA-Lyon, MATEIS CNRS \\ ${ }^{1}$ Ukraine \\ ${ }^{2}$ France
}

\section{Introduction}

Iron ore sinter is obtained by complex processes involving partial smelting of sinter mixture components under conditions of solid fuel combustion in the sintered bed. A simplified scheme of the iron ore sintering process is represented by Fig. 1.

Sinter mixture contains such components as iron ore, solid fuel (usually coke breeze), flux and some additives (e.g. solid wastes like steelmaking slag, gas cleaning dust and sludge etc). The mixture is granulated with the addition of moisture and then loaded to the travelling grate of the sintering plant.

Size distribution and durability of the granules influence both the green bed structure and permeability, thus affecting the sintering productivity and the quality of the sinter (Ellis et al, 2007; Khosa \& Manuel, 2007; Naakano et al, 1998; Haga et al, 2005). Granules should not only endure mechanical stresses. They must also withstand destruction under conditions of overmoisturising in the moisture condensation zone of sinter plant. Therefore, study of the structure of granules produced from the sinter mixtures of different compositions is important. Traditional techniques (i.e. optical microscopy) give very limited information providing only random pictures of the structure at the surface of a single cross-section. Moreover, being formed without additives of a binder, granules are very fragile and prone to destruction when dried, which makes study of their internal structure difficult.

On the grate of sintering plant suction is imposed to the bed by the exhauster fan via windboxes (conic pots collecting gas below the travelling grate), gas header and gas cleaning system. After ignition of the solid fuel combustion zone propagates downwards, finally reaching hearth bed layer formed with the sinter return (under screen product $<10 \mathrm{~mm}$ ). Complex processes involving partial smelting of raw materials are resulted in formation of the sintered product.

The product of sintering is a porous lumpy material formed of particles with an irregular shape coalesced due to a binding effect of the solidified melt. The accumulated porosity of a piece of sinter consists of inter-particle voids and intra-particle pores (Debrincat et al, 2004; 
Higuchi et al, 2004; Kokubu et al, 1986). The morphological parameters of the porosity such as total porosity pore size distribution, proportion of open and closed pores etc., correlate with specific surface area thus affecting both mechanical and physicochemical properties of sinter.

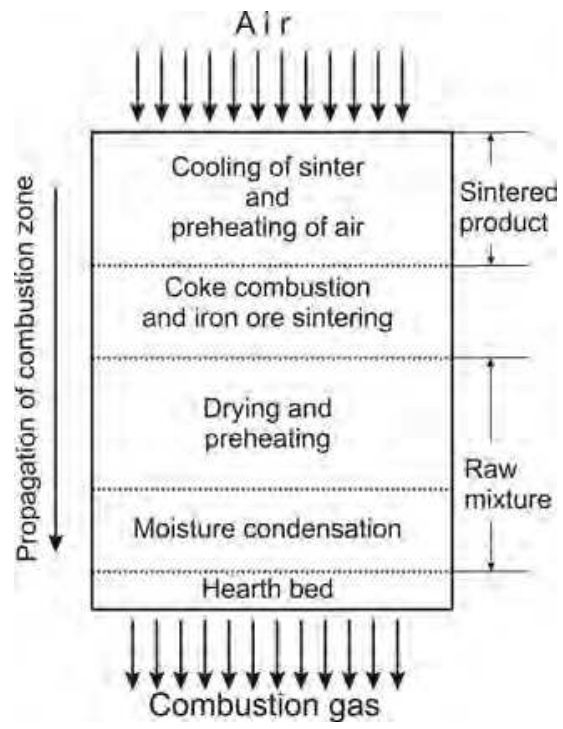

Fig. 1. Scheme of the iron ore sintering process.

The most widely used method for estimating sinter porosity is the mercury porosimetry. However, this method is destructive - it is usually impossible to re-use exactly the same samples for further investigations (e.g. reducibility test) as they are polluted with mercury. Another disadvantage is that the method characterises the size of the access window to the volume of the pore and not really its equivalent diameter; moreover, the material may exhibit so called "closed" pores with no connection to the outer surface, which cannot be measured by mercury porosimetry.

In our previous studies (Shatokha et al, 2009, 2010) a possibility to study the structure of sintering mixture granules and morphology of pores in the sintered product using 3D imaging technique, X-ray tomography, enabling non-destructive investigation of these complex heterogeneous materials, was demonstrated. In this research X-ray tomography technique was applied along with some other experimental methods to study microstructures of sinter granules and of sinter, and their relationship with the materials' properties.

\section{Experimental}

\subsection{Sintering techniques}

Sintering experiments were conducted at the National Metallurgical Academy of Ukraine. Characteristics of the sinter mixtures are given at the Table 1 . The quantity of return in the 
mixture was $20 \%$ with coke breeze share at 6.5-7.0 \% - depending upon consumption of the limestone. Ukrainian raw materials were used such as hematite ore and magnetite concentrate of Kryvyi Rih deposit (Table 2) and limestone of Yelenovskoye deposit. Mixtures were granulated in a laboratory granulation drum with a moisture addition of 7.5$8.0 \%$. Sintering was conducted in the laboratory pots (steel cylinders) with the grate area of $0.005 \mathrm{~m}^{2}$ and a height of $0.25 \mathrm{~m}$.

\begin{tabular}{|l|c|c|c|c|c|c|c|c|c|c|}
\hline & 1 & 2 & 3 & 4 & 5 & 6 & 7 & 8 & 9 & 10 \\
\hline Basicity, $\mathrm{CaO} / \mathrm{SiO}_{2}$ & \multicolumn{3}{|c|}{0.8} & \multicolumn{3}{|c|}{1.4} & \multicolumn{3}{|c|}{2.0} \\
\hline Concentrate/ore mass ratio & $20 / 80$ & $50 / 50$ & $80 / 20$ & $20 / 80$ & $50 / 50$ & $80 / 20$ & $20 / 80$ & $50 / 50$ & $80 / 20$ & 100 \\
\hline
\end{tabular}

Table 1. Characteristics of the sinter mixtures.

\begin{tabular}{|l|l|l|l|l|l|l|l|l|l|l|l|l|l|}
\hline & $\mathrm{Fe}$ & $\mathrm{Mn}$ & $\mathrm{P}$ & $\mathrm{S}$ & $\mathrm{FeO}$ & $\mathrm{Fe}_{2} \mathrm{O}_{3}$ & $\mathrm{SiO}_{2}$ & $\mathrm{Al}_{2} \mathrm{O}_{3}$ & $\mathrm{CaO}$ & $\mathrm{MgO}$ & $\mathrm{TiO}_{2}$ & $\mathrm{~K}_{2} \mathrm{O}+\mathrm{Na}_{2} \mathrm{O}$ & $\mathrm{LOI}$ \\
\hline Ore & 55.12 & 0.062 & 0.089 & 0.025 & 0.95 & 77.7 & 10.3 & 5.8 & 0.14 & 0.34 & 0.157 & 0.71 & 3.4 \\
\hline Concentrate & 63.75 & 0.039 & 0.017 & 0.033 & 27.98 & 59.97 & 9.69 & 0.41 & 0.35 & 0.61 & 0.04 & 0.27 & 0.49 \\
\hline
\end{tabular}

Table 2. Chemical composition of the iron ores, used for sintering (mass \%).

\subsection{The principle of X-ray tomography and its application to study the iron ore material}

The principle of X-ray tomography and its application in the field of materials science are explained in details by Maire et al (2001). This non-destructive technique is analogous to medical scanner and allows, from X-ray radiography acquired around a single axis of rotation, to generate a 3D image of the internal structure of an opaque material. The reconstruction involves a computed step and the final image is a 3D map of the local X-ray attenuation coefficient.

X-ray scanning of the samples was performed using the tomograph of the MATEIS laboratory at INSA de Lyon (Lyon, France), a Vtomex system, manufactured by Phoenix Xray.

The beam was operated at $90 \mathrm{keV}$ and $170 \mu \mathrm{A}$ with no filtering for the observations made in this study. The highest resolution achieved was $2.85 \mu \mathrm{m}$; however because of the trade-off between the resolution and the maximum specimen dimension (e.g. whole pieces of sinter sized from 9 to $25 \mathrm{~mm}$ were investigated) the average resolution used in this study was $20 \mu \mathrm{m}$. Under given beam parameters and achieved resolution it appeared impossible to make precise phase analysis of the sinter although the images obtained were quite suitable for the analysis of the porosity because the solid phase absorbs the X-rays much better than air.

The tomography setup used is equipped with a standard laboratory X-ray tube, the source is then not monochromatic. Therefore, the values of the attenuation coefficients measured are 
not absolute values as the exact energy distribution in the incident beam is not well known. The measured apparent value of the attenuation constituent of different phases imaged in this study is shown in Fig. 2. Standard samples made of pure $\mathrm{Cr}, \mathrm{Fe}, \mathrm{Zn}$ were also scanned and Fig.3 shows the measurements performed with these standards: the measured coefficients are in a reasonable qualitative agreement with what could be expected for these materials.

As the preparatory step, several cross-sections were prepared and initially studied using optical microscopy and afterwards - using tomography method. Based on this experience authors were able to master recognition of the sinter mixture components (coarse and fine particles of ore, sinter return, limestone and coke breeze) in undistorted granules. At the same time, the resolution used for acquisition constrained the quality of the images. Therefore, it was not possible to recognise the nature of particles smaller than $0.1 \mathrm{~mm}$ in this study. A possibility of distinguishing various phases in the sinter structure (e.g. calcium ferrites, olivines, hematite, magnetite and so on) was also limited due to the same reason.

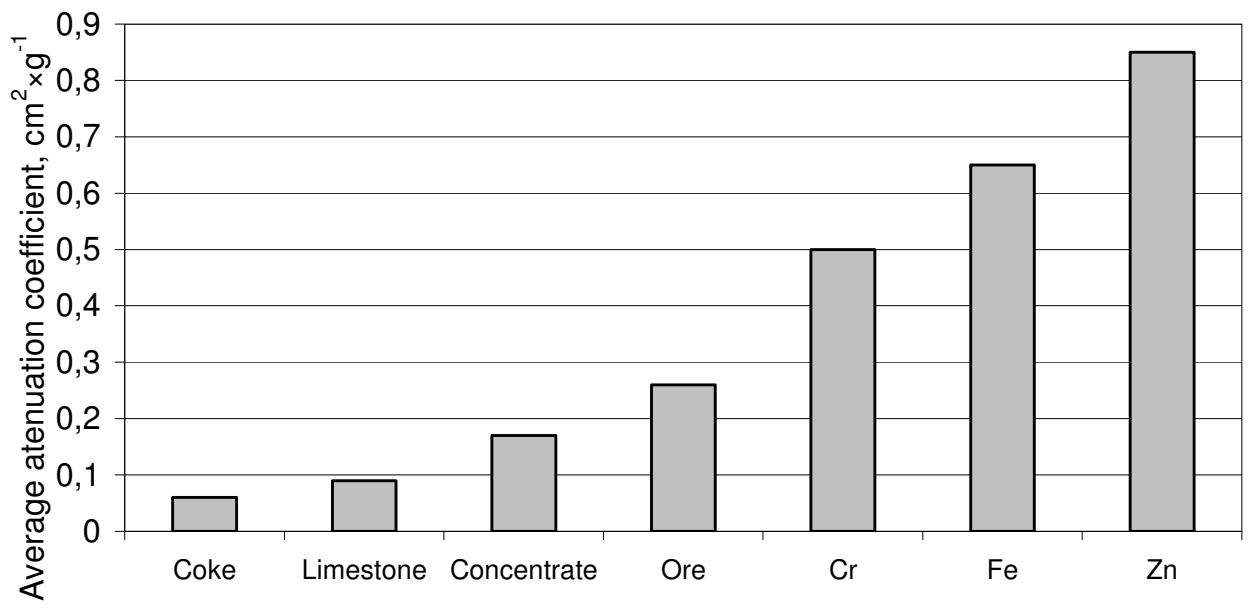

Fig. 2. Average attenuation coefficient measured in the reconstructed images for the studied materials and for three pure standards using an acceleration voltage of $100 \mathrm{kV}$.

\subsection{Methodology of the porosity estimation using 3D X-ray tomography}

In the present paper all empty space inside the sample surface i.e. inter-particle voids and intra-particle pores is referred to as pores. After X-ray scanning of the sample following procedures were applied to analyse the porosity parameters:

- $\quad$ Reconstruction from the obtained projections of the 3D images using the commercial DatosX_rec software (from Phoenix X-ray)

- Binarisation of the image using the ImageJ freeware (http:/rsb.info.nih.gov/ij) with a classical threshold. The solid phase of the sample was attributed the maximum grey 
level (255) and pores plus the surrounding air were attributed the minimum level (0). An example of a typical slice of 3D image before and after binarisation is shown in Fig.3.

- Calculation of the volume of solid material. A homemade plug-in was used to calculate the fraction of white pixels for each 2D slice. Total amount of white pixels gives the total volume of material $\left(\mathrm{V}_{\mathrm{m}}\right)$.

- $\quad$ Separation of open and closed porosity. A region growing procedure was used to select the open pores plus the outside air. Fig.4 represents an example of a typical slice of 3D image before (a) and after (b) region growing procedure. Then it was possible to calculate volume of the material plus volume of closed pores $\left(V_{m}+V_{c . p}\right)$. Finally the volume of closed pores is obtained by the difference of these two quantities

$$
\left(\mathrm{V}_{\mathrm{m}}+\mathrm{V}_{\text {c.p }}\right)-\mathrm{V}_{\mathrm{m}}=\mathrm{V}_{\mathrm{c} . \mathrm{p}}
$$

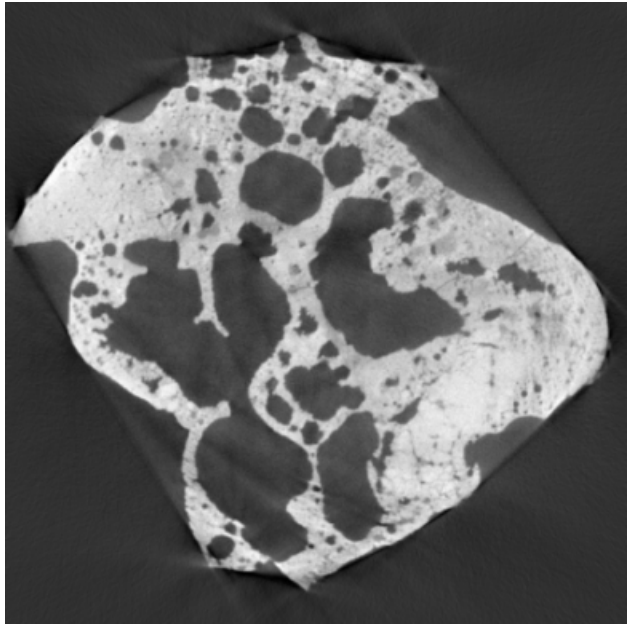

(a)

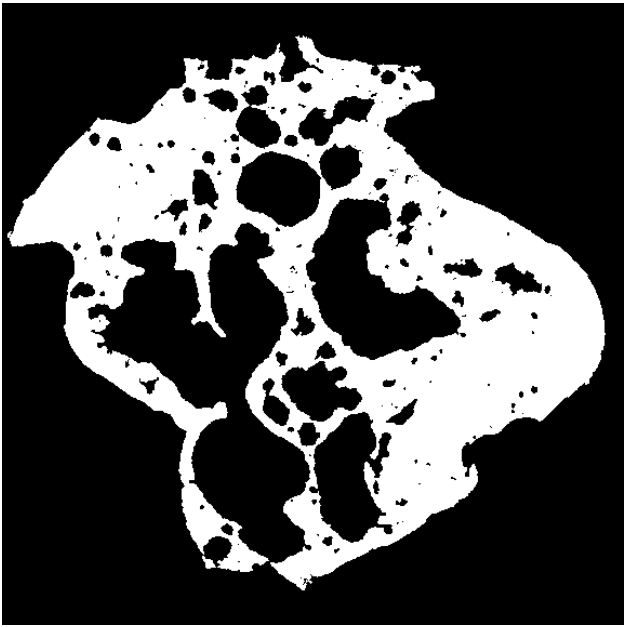

(b)

Fig. 3. Typical slice of 3D image before (a) and after (b) binarisation (white - solid phase, black - gaseous phase).

After completion the procedures, different pores were separated via a $3 \mathrm{D}$ watershed type technique. A homemade plug-in system was then used to measure the morphological properties of each open pore (e.g. total volume and equivalent spherical diameter) and to indicate if the pore touches the frame of the 3D reconstruction scan. The pores touching the frame of the scan were assumed to belong to the outside air and they were then excluded from the analysis.

The closed porosity was then separated by making the difference between the open porosity (selected by the region growing procedure as described before) and the total porosity (selected by a simple grey level threshold based on the same value of the grey level as the one used for the region growing). The Fig. $4 c$ shows an extracted slice with separated closed porosity. The morphology of each closed pore was then calculated in the same way as for the open porosity. 


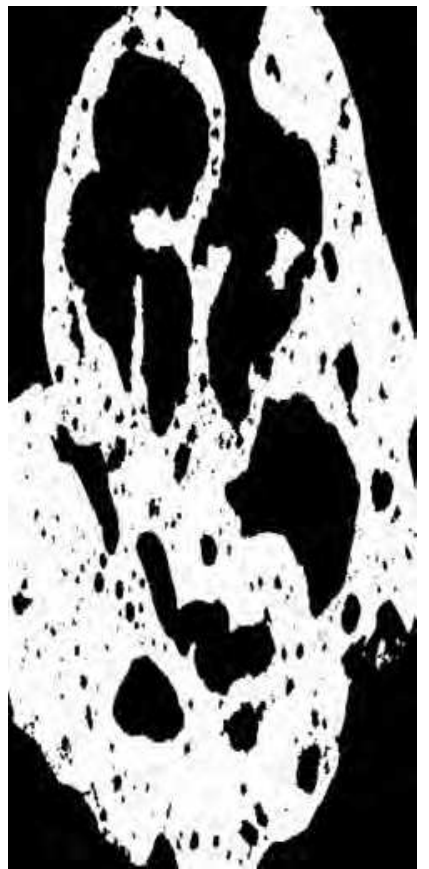

(a)

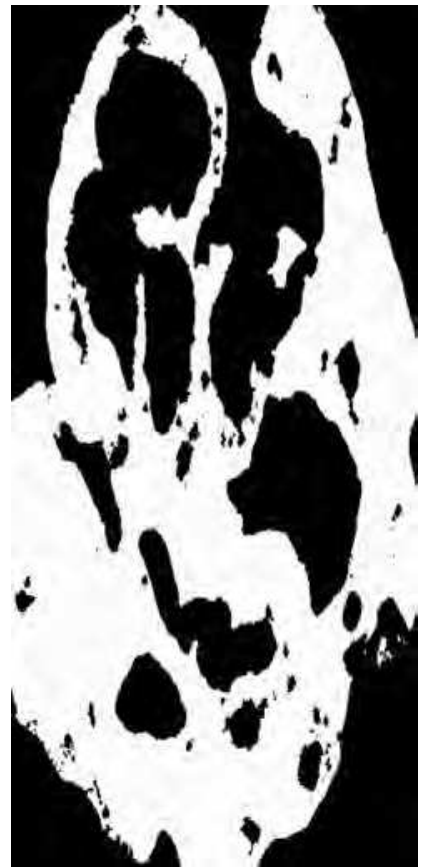

(b)

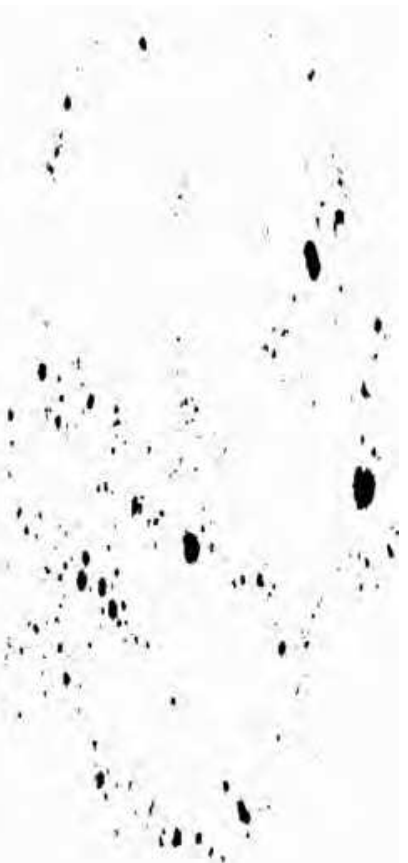

(c)

Fig. 4. Reconstructed slice showing the total porosity after binarisation (a), open porosity after region growing (b) and closed porosity (c).

\section{Results and discussion}

\subsection{Morphology of the sinter mixture granules}

The granules are formed in sinter mixture due to molecular and capillary forces caused by moistening. Following mechanism is generally accepted:

- $\quad$ particles sized over 1.0-1.5 mm act as nuclei (granule centres);

- $\quad$ superfines, sized below $0.05 \mathrm{~mm}$, adhere to the surface of nuclei;

- $\quad$ particles of $0.05-0.75 \mathrm{~mm}$ may adhere to the layer of superfines.

Particles of intermediate size (from 0.75 to $1.0 \mathrm{~mm}$ ) are sometimes considered as being problematic: they are not large enough to serve as a nucleus for granulation and they are too big to adhere to the surface of existing nuclei. Sinter producers usually take this concept into account while designing requirements for the sizing of the sinter mixture components (Ellis et al, 2007).

Optimal sinter mixtures design in the modern and future conditions is constrained by the following factors (Hunt, 2004, Makkonen et al, 2002, Shatokha et al, 2011):

- the growing deficit of rich coarse iron ores and the corresponding increase of the fineness of ores used for sintering; 
- in many cases the only opportunity to keep iron content in the sinter product at the level required by customers is to increase significantly the amount of deeply enriched iron ore concentrate with over $90 \%$ of superfines sized below $0.04 \mathrm{~mm}$ in the sinter mixture;

- $\quad$ sinter plant is usually considered as the facility needed to recycle fine ferrous wastes (gas cleaning dust and sludge, steelmaking slag, rolling mills scale etc), which sometimes makes unavoidable introduction to the sinter mixture essential quantity (mass share may reach as much as $20 \%$ and more) of such - not perfectly suited for the sintering technology - materials.

Mentioned above may cause deviation of the real granulation behaviour in the sinter mixture from the generally accepted mechanism. These factors are connected with the increase of the share of various superfines (not only iron ore concentrate, but also wastes such as e.g. wet gas cleaning sludge), the role of which in the sintering mixture towards the granulation behaviour, process parameters and quality of final product remains in the focus of many researchers (Ellis et al, 2007, Khosa \&Manuel, 2007, Naakano et al, 1998, Haga et al, 2005).

Structure of granules depends on adhering fine and nuclei ratio, moisture content, lime and wastes addition, water absorption capacity of the mixture components etc. (Mou et al, 2007). Bonding of particles in the granule is very weak which makes problematic preparation of section for microscopy analysis. Moreover, irregular form of nuclei and chaotic adhesion of fines decrease representativeness of study based on analysis of a random slice. Therefore application of new, non-destructive experimental methods for studies of the granules' structure is very promising.

Fig. 5-7 demonstrate morphology of the granules obtained from mixtures with the same basicity of 1.4 and with various share of concentrate corresponding to samples 4-6 in Table 1.

Structure of granule, obtained with the lowest share of concentrate (Fig. 5) generally corresponds to the "classic" understanding of sinter mixture granulation mechanism described above. This granule is formed around the large porous particle of a sinter return with an adhered layer of fines (dark). On the outer surface of the fines' layer it is possible to recognise the particles of an intermediate size (well below $0.5 \mathrm{~mm}$ ).

In granule with the medium share of concentrate the volume of the adhered fines layer becomes generally larger. However, the layer develops unevenly around the nucleus, in a way that the granule has a "front" with thin layer of fines and a "tail" with thick one, which perhaps owes to the granulation dynamics (Fig. 6).

Granule, obtained from the mixture with largest share of concentrate (Fig. 7) has much more regular shape, quite similar to those of pellets (another type of iron ore material, produced from fine concentrate with additives of binder). This granule has a coarse particle of ore inside which could be assumed as nucleus. However, it contains also a distinct spherical clod of fines, which might be formed by concentrate around a drop of water and could be considered as pseudo-particle, potentially able to serve as the nucleus itself. 

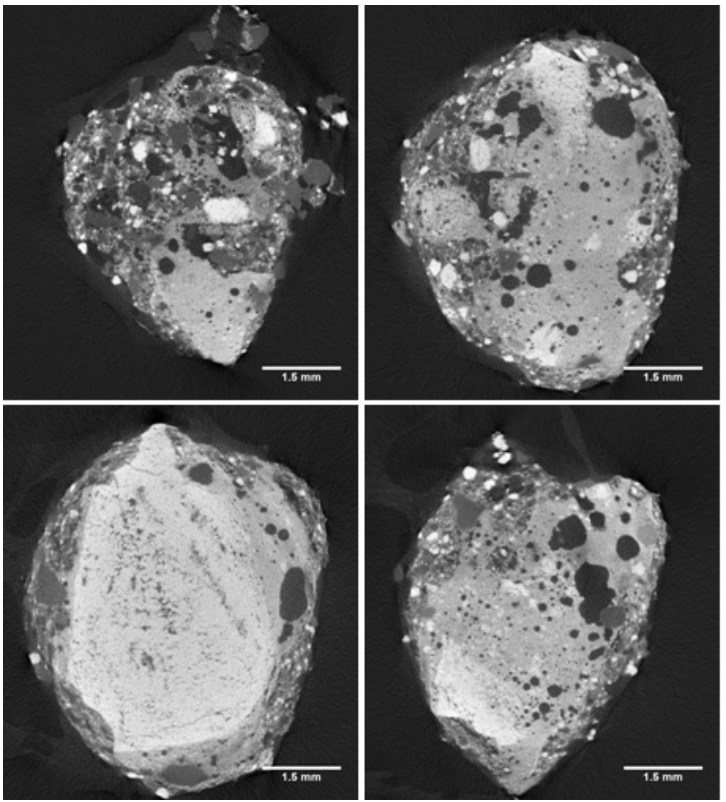

Fig. 5. Reconstructed slices of a granule (sample \#4 in Table 1, four parallel sections). Almost entire granule's volume is occupied by sinter return particle (light grey matter of irregular shape with black pores) sized over $5 \mathrm{~mm}$.

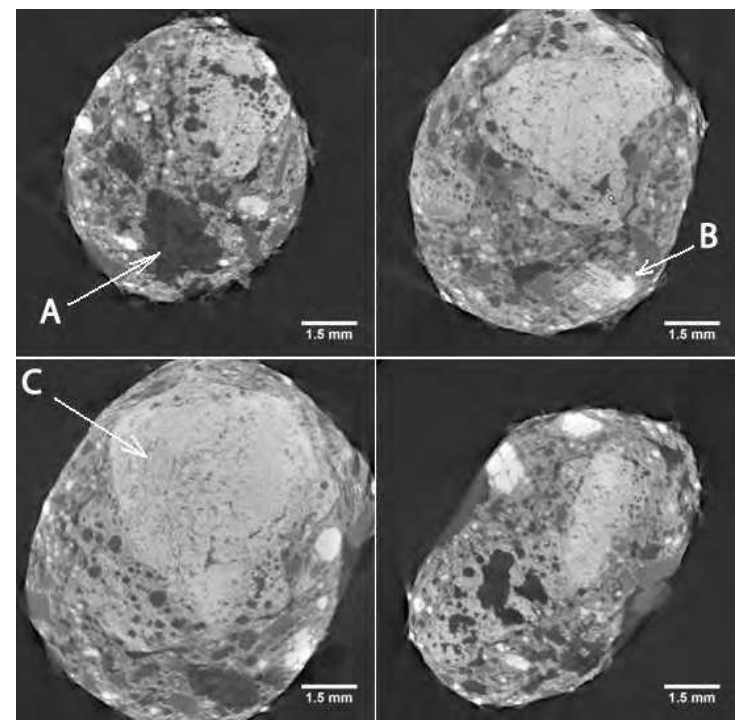

Fig. 6. Reconstructed slices of a granule (sample \#5 in Table 1, four parallel sections): A - coke breeze, B - ore, C - sinter return, served as nucleus. 

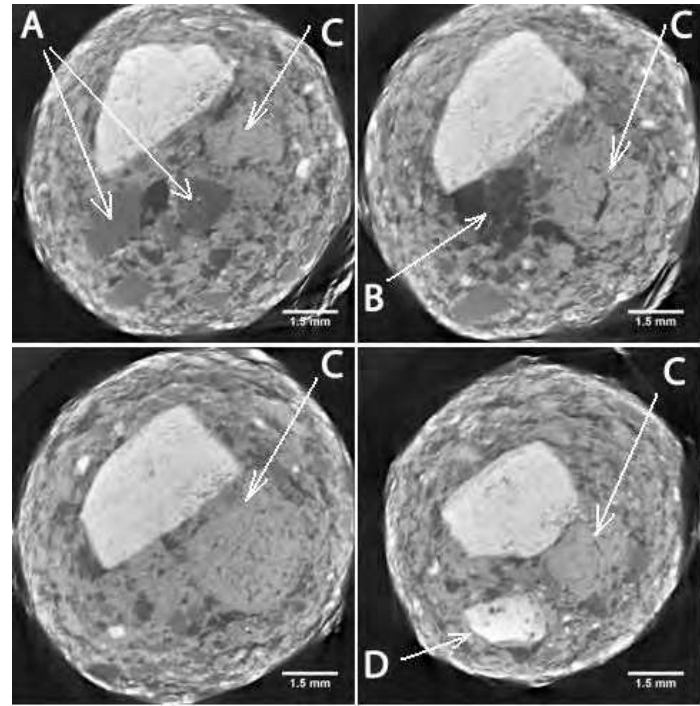

Fig. 7. Reconstructed slices of a granule (sample \#6 in Table 1, four parallel sections): A - limestone, B - coke breeze, C - clod of iron ore concentrate, D -ore.

Application of X-ray tomography method enabled authors to study 3D structure of the granules and to perform their systematic typological analysis. In particular, it was found that the granules could be classified by the contribution of the share of adhering fines layer, formed at the surface of the nucleus, in the total radius of the granule. Three types of granules, different by adhering fines layer thickness, are represented in Fig.8 - both schematically and with the real samples.
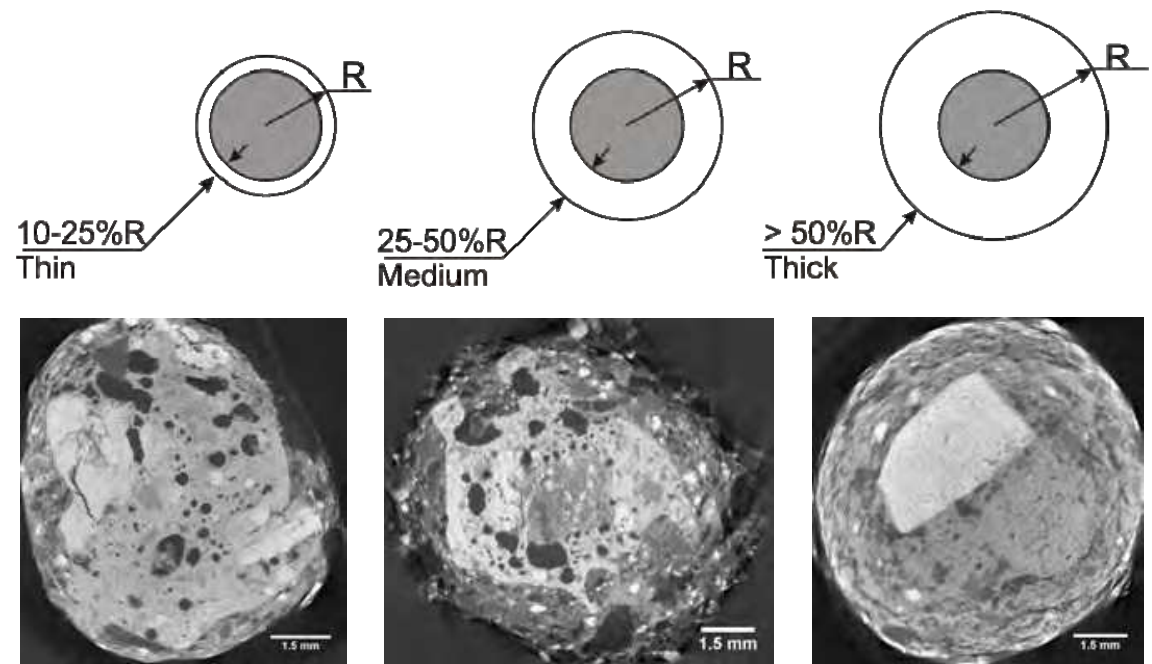

Fig. 8. Classification of the granules by the thickness of the adhering fines layer and real examples of each type. 
Statistics of the shares of three types of granules in the granulated sinter mixtures versus the concentrate/ore ratio is shown in Fig.9. The increase of the concentrate/ore ratio in a sinter mixture leads to the decrease of the share of the granules with a thin and a medium thickness of the adhering fines layer. Correspondingly, the share of the granules with a thick adhering fines layer increases. Obviously, this effect is caused by the decrease of the number of coarse particles in a sinter mixture, able to serve as nuclei for the future granules with a simultaneous growth of the share of fines able to adhere to the nuclei or to the granules surface.

Introduction of the increased amounts of concentrate to the sinter mixture makes granulation more complex: superfine particles not only adhere to coarser ones but may also form durable nuclei while binding particles of intermediate size and the more superfines are used in the sinter mixture the less predictable is the size distribution of granules (Korotich, 1978).

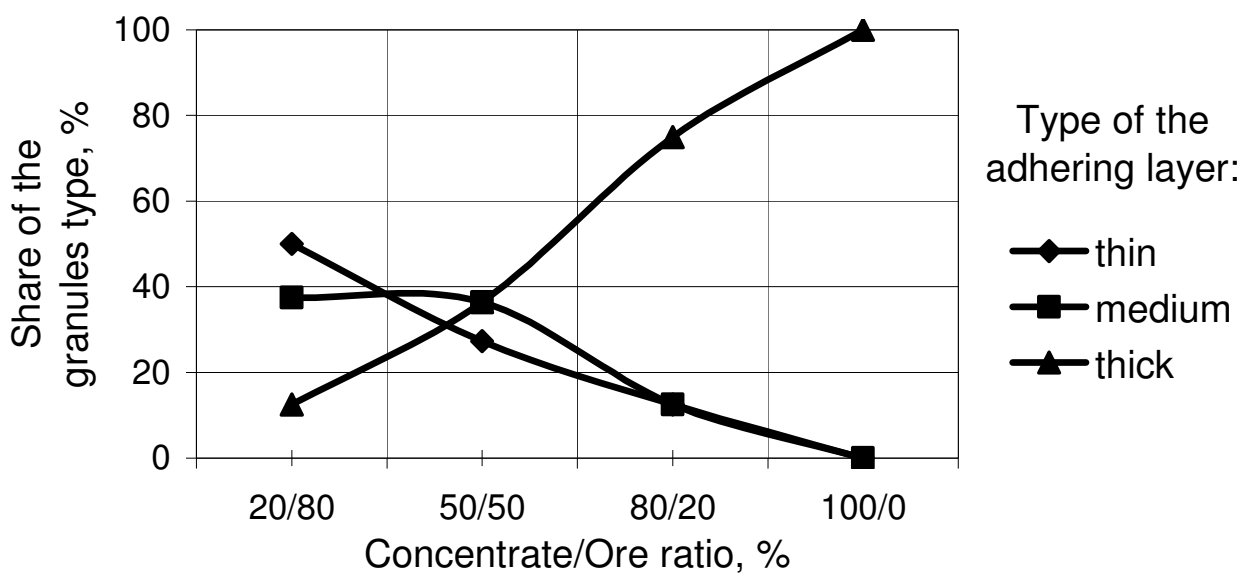

Fig. 9. Influence of the Concentrate/Ore ratio in a sinter mixture on the distribution of granules by the adhering fines layer thickness.

X-ray scanning confirms that sometimes the mechanism of granules formation is more complex than it is generally considered. For example, some of the granules, particularly those with a thick adhering layer, contain almost undistorted spherical granules of smaller $(<2 \mathrm{~mm})$ diameter embedded in this layer. This means that some of the initially formed microgranules may not develop into independent granules. However, they may act as pseudo-particles, adhering to other granules and finally becoming a part of bigger granules. In some cases, granules formed as a result of the coalescence of two or three granules of similar size were observed. Examples of the granules with abnormal morphology are represented in Fig. 10. Effect of their presence on the sintering behaviour and quality of the final product requires further study. 


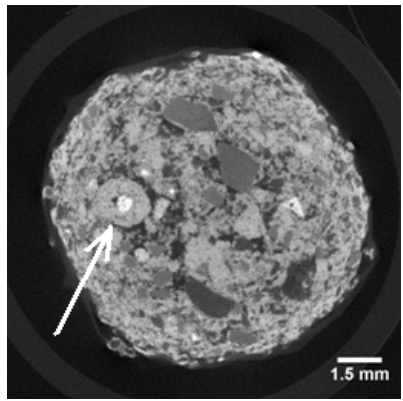

(a)

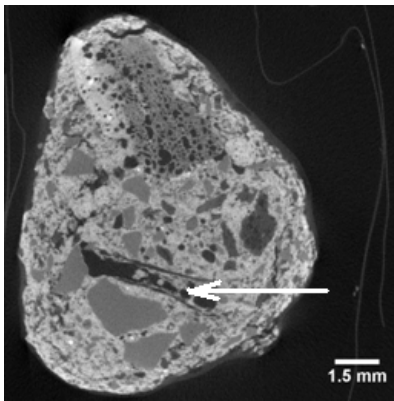

(b)

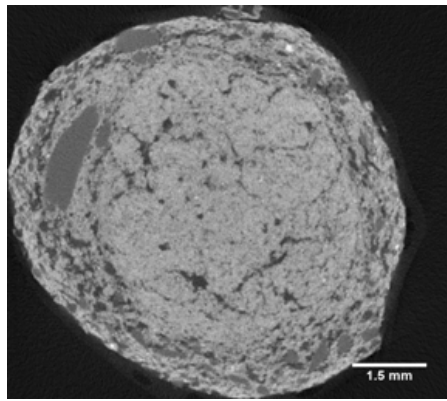

(c)

Fig. 10. Examples of granules with abnormal structure: (a) small granule embedded inside the adhering layer; (b) remains of the boundary of two granules coalesced to form a bigger granule; (c) pellet-like granule with no nucleus.

\subsection{Porosity of sinter}

Development of pores in iron ore sinter is very complex process involving generation of gaseous phase due to combustion of fuel, decomposition of limestone, vaporisation of water etc under conditions when part of material smelts, forming liquid slag prone to foaming (e.g. due to reaction of $\mathrm{FeO}$ with carbon).

In particular, it was demonstrated by Yang \& Standish (1991) that pores may form at the sites of limestone particles due to complex process, involving decomposition, reaction of lime with iron ore particles, and formation of calcium ferrites, which then get melted and the melt reacts with other particles. The porosity of the studied sinters as a function of the basicity is shown in Fig.9 separately for open and closed pores.

In our study a significant drop of open porosity for all sinters was observed with an increase of basicity from 0.8 to 1.4 which is in agreement with the opinion (Kokubu et al, 2004; Yang \& Standish, 1991) that porosity decreases with increasing basicity due to the increased amount of the melt. However, further increase of basicity to 2.0 leads to a less significant change of open porosity. Moreover, for the sinter series produced with maximum concentrate share in the mixture porosity reduces, while for the others there is a tendency to increase porosity.

For the slag systems representing the melt produced in the sintering processes a basicity of 1.4 lies near the eutectic area and as basicity increases slag liquidus temperature also augments (Slag atlas, 1995). Hence, further basicity increase under the same heat conditions might be followed by formation of a more heterogeneous and consequently more viscous and less mobile melt. This may explain the observation that the sinter porosity does not alter as basicity increases from 1.4 to 2.0 .

The tendency of porosity to reduced drop only for the sinter produced with the maximum share of concentrate as basicity increases to 2.0 might be explained by additional heat produced from oxidation of concentrate's magnetite accompanied with generation of larger quantity of the melt. 
For the closed porosity no clear relationship with the basicity was observed. Probably formation of this type of the pores is less affected by the melt properties or governed by some other phenomena. E.g. there is the hypothesis (Korotich, 1978) that the closed pores are formed due to the evolution of the carbon monoxide from direct reduction of iron oxides as a result of the interaction with the fine solid fuel particles rolled-in to microgranules. Later study of Yang \& Standish (1991) confirmed that pores are formed at sites of coke particles after their burn out.
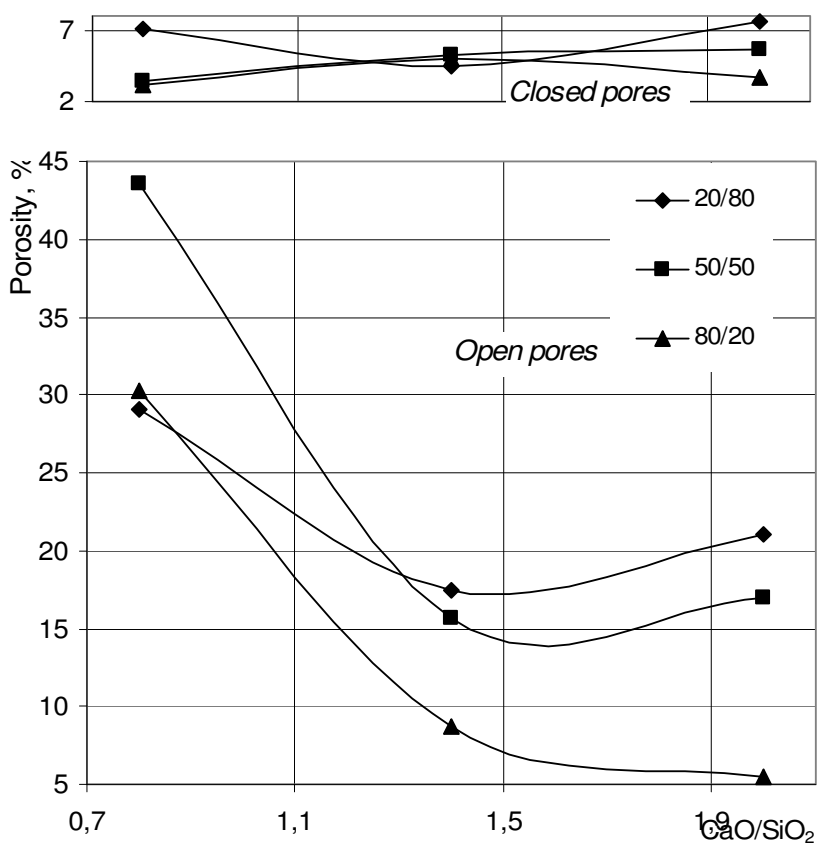

Fig. 11. Effect of sinter basicity at different concentrate/ore ratios on open and closed porosity.

The comparison of the data on open porosity obtained using 3D tomography and with the mercury test (sinter obtained from burden with $50 \%$ of concentrate at the ore/concentrate mix) is shown in Fig.12. The higher values obtained using 3D tomography can be explained by the narrow range of the measured pore intrusion diameter - from 329 to $0.01 \mu \mathrm{m}-$ provided by the porosimeter used in this study. This means that a very significant portion of the sinter pores was not measured in the mercury intrusion test.

Fig.13 and Fig.14 compare the porosity measurement by the share of the volume related to the pores of given size, obtained by both methods for the similar range of pore sizes (only pores under $300 \mu \mathrm{m}$ were taken into account for the tomography method). They demonstrate inherent incomparability of the results: the tomography method enables characterisation of the pores by their equivalent diameter, while mercury porosimetry - by their intrusion diameter -and large pores may have relatively small intrusion diameter (i.e. access window). 


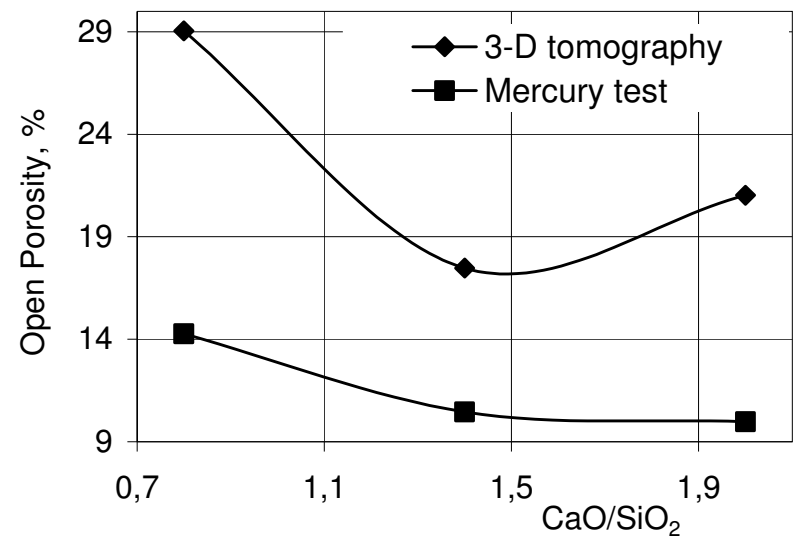

Fig. 12. Comparison of the data on open porosity obtained using 3-D tomography and mercury test (sinter produced from the mixture with ore/concentrate ratio of 20/80).

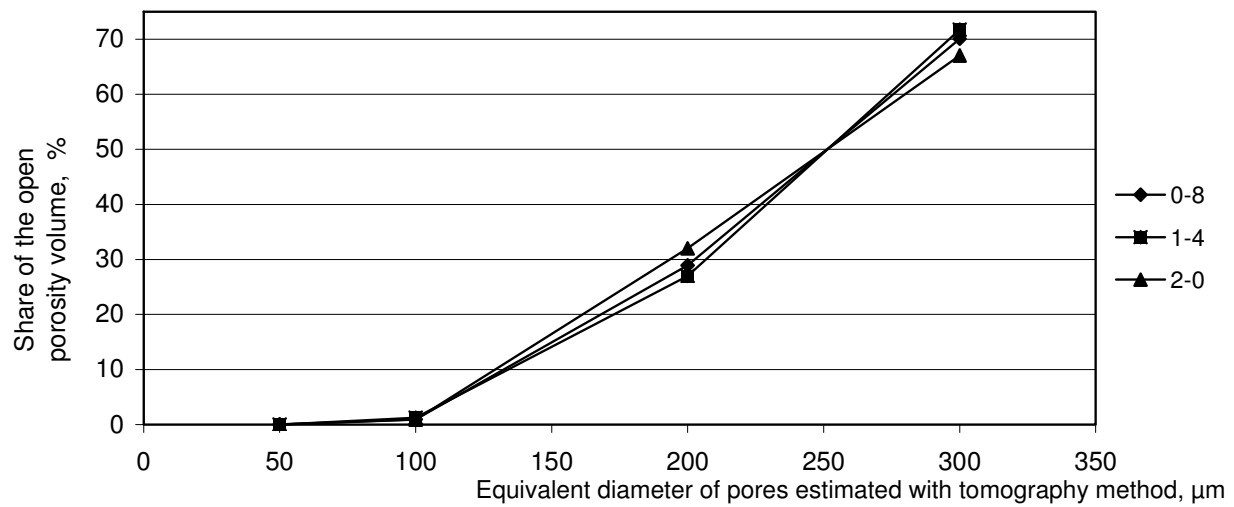

Fig. 13. Open porosity volume, related to pores with equivalent diameter under $300 \mu \mathrm{m}$ measured by tomography.

The frequency distributions of the equivalent diameter of the open pores are shown in Fig. 15. Demonstration of the pore size distribution by the volume occupied by pores of certain size appears less informative: over $85-90 \%$ of the porosity volume belongs to very few pores larger than $500 \mu \mathrm{m}$. The frequency distributions are right-skewed with single peaks for a pore diameter of about $200 \mu \mathrm{m}$ for almost all types of sinter, which is quite close to the average size of the pores in the range 148-159 $\mu \mathrm{m}$ (Hosotani et al, 1996), though data for open and closed pores were not distinguished in the given reference. 


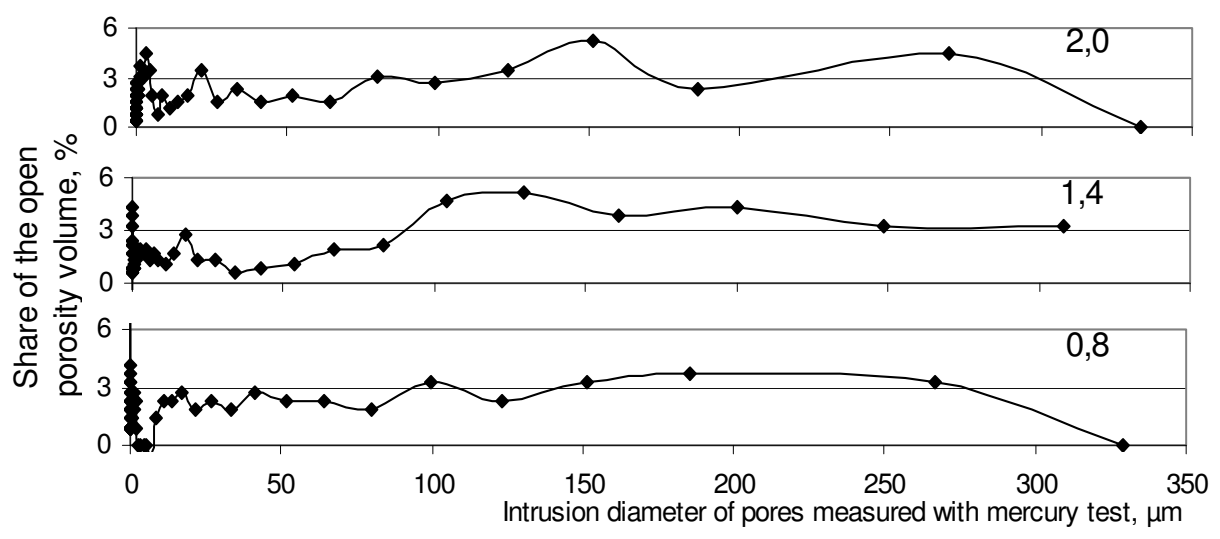

Fig. 14. Open porosity volume, related to the open pores with given intrusion diameter measured by the mercury porosimetry method.
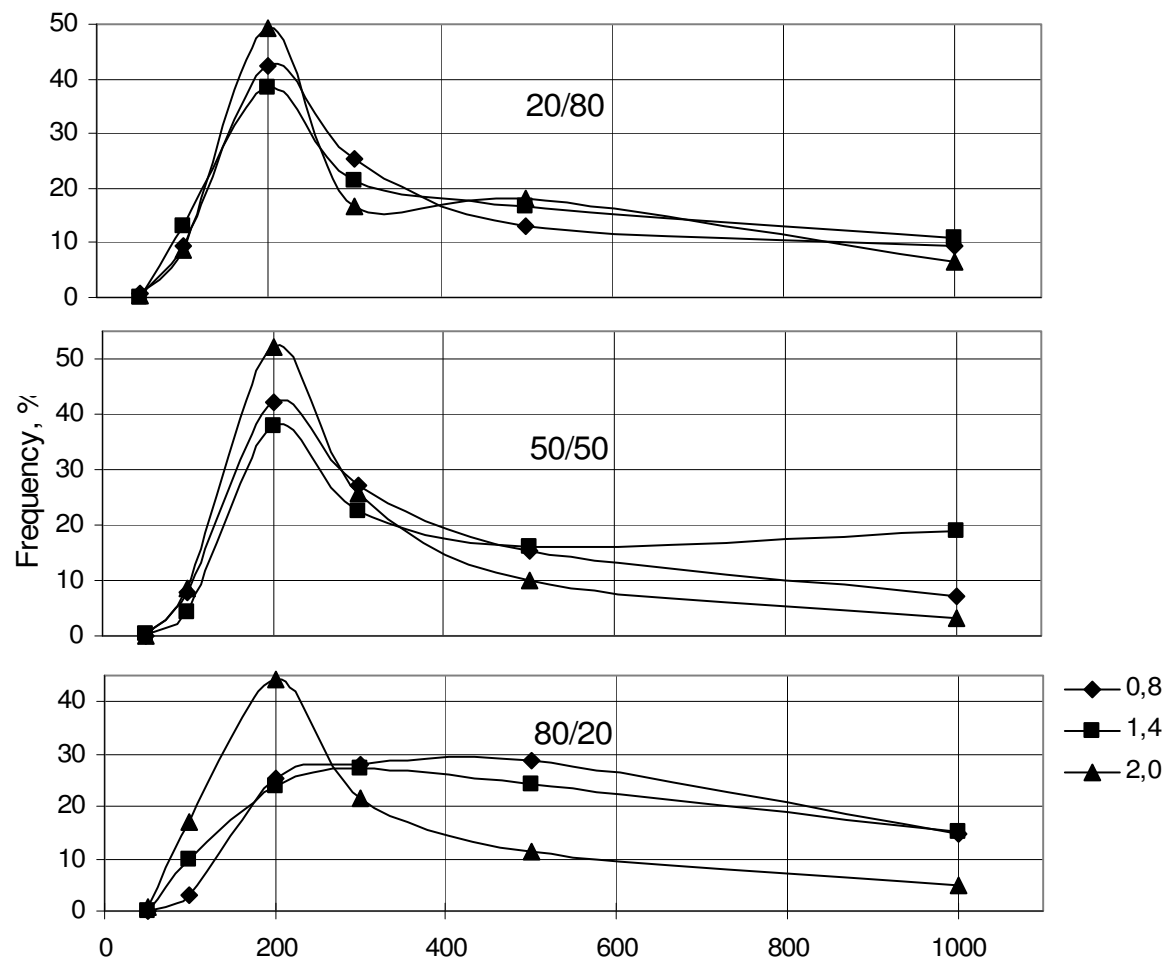

Equivalent diameter of pores, $\mu \mathrm{m}$

Fig. 15. Frequency distribution for equivalent diameter of open pores at basicities of $0.8,1.4$ and 2.0 for sinters produced from mixtures with concentrate/ore ratios of 20/80, 50/50 and $80 / 20$. 
Used resolution was sufficient to obtain information about the pore or piece of solid material with a lateral side of approximately $20 \mu \mathrm{m}$. However, during the watershed procedure, part of the open pores with equivalent diameter equal to 2-3 pixels (i.e. $40-60 \mu \mathrm{m}$ ) and smaller could be lost. Therefore it is possible to assume that open porosity under $60 \mu \mathrm{m}$ is underestimated in the present study. According to Higuchi et al (2006) micro-porosity below $15 \mu \mathrm{m}$ accounts for about 13\% and Bhagat et al (2006) report that the micro-porosity below $10 \mu \mathrm{m}$ accounts for $5.23-10.38 \%$ of the total porosity.

It must be mentioned that pores with a diameter larger than the mean free path of the reducing gases molecules (approximately $0.0004 \mu \mathrm{m}$ in average at $1000 \mathrm{C}^{\circ}$ and under a pressure of $10^{5} \mathrm{~Pa}$ (Lide, 2004) are considered as important in terms of their influence on the reducibility (Manchinskiy \& Shkodin, 1963). Therefore further research using 3D tomography facilities with higher resolution would be helpful to measure the morphological parameters of the micro-porosity.

The sharpest peaks are always observed for the sinters with a basicity of 2.0. The curves corresponding to sinters of 0.8 and 1.4 basicities are very similar. The open pore size distribution curves for the sinters, obtained from mixtures with concentrate/ore ratios of $20 / 80$ and of 50/50, are also similar. An increase of the concentrate share to $80 \%$ is accompanied by a softening of the peak for the sinter with basicity 2.0 and a shift to larger diameters.

\subsection{Effect of porosity on the reducibility of sinter}

Three sinter samples with different basicites from the series with concentrate/ore ratio of $50 / 50$ were used for the reducibility test. It was considered as being very important for this test to use the samples previously analysed by tomography. Hence, it was not possible to determine the exact chemical composition of particular samples. Therefore, instead of the reduction degree, data on the weight loss (current in per cent of total) were used (Fig.16) as the reducibility characteristics.

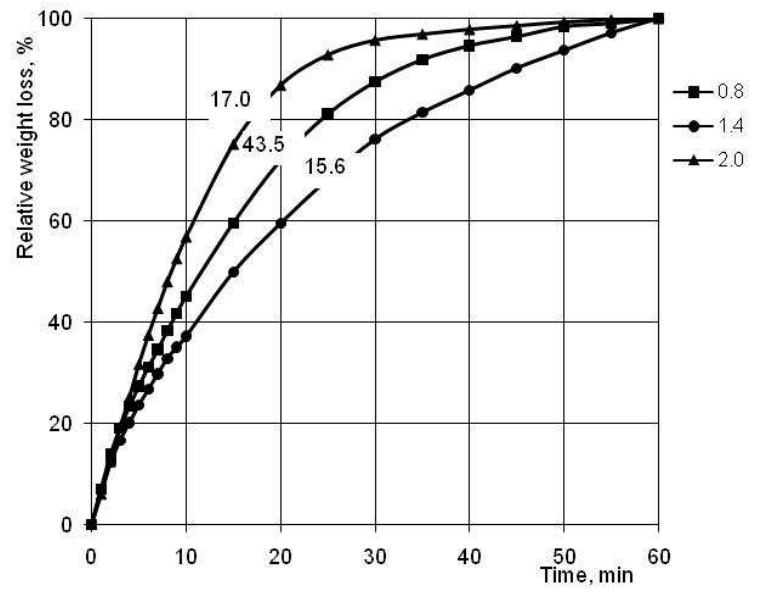

Fig. 16. Relative weight loss during reduction test for sinters with different basicities: (figures at the curves - open porosity in \%). 
The most intensive weight loss, observed for the basicity of 2.0, is in agreement with the existing knowledge and can be explained by the formation of more reducible calcium ferrites. However, more intensive reduction of sinter at the basicity of 0.8 to compare with those at 1.4 was less expected because in this range, an increase of reducibility with the increased basicity is normally observed for industrial sinters produced from the same raw materials (Katsman et al, 1986). This result might be explained by much higher porosity level observed for the sinter with basicity of 0.8. Positive effect of sinter porosity on its reducibility has been stated by many authors (Higuchi et al, 2004; Hosotani et al, 1996; Bhagat et al, 2006).

\section{Conclusions}

The X-ray tomography method was applied for the investigation of the internal structures of sinter mixture granules and sinter. The method has important advantages over the methods used so far for this kind of materials, allowing non-destructive characterisation of the microstructure in the bulk. Following main results were obtained:

1. Various components of the sinter mixture like iron ore, concentrate, coke breeze and limestone can be identified in the granules and it is possible to estimate their size and spatial distribution.

2. A novel approach for the classification of granules by the thickness of the adhering fines layer in a proportion to the whole granule radius has been suggested. It was shown that the growth of concentrate's share in a sinter mixture leads to a statistically increased presence of granules with a thicker adhering layer (more than a half of the granule's radius).

3. Deviation of the granules structure from the generally accepted granulation model was observed when the share of concentrate in the mixture was increased. Abnormal structures of some granules have been observed: microgranules embedded in the adhering layer of bigger granules; granules formed as a result of the coalescence of two or more granules of similar size; granules formed without coarse nucleus particle, with a structure similar to this of pellets.

4. For the sinter product tomography method allows obtaining of the data on the volume and equivalent diameter of each pore, thus providing the possibility to analyse open and closed pores separately.

5. Influence of the sinter basicity on the open porosity is associated with the quantity and properties of the melt formed during sintering. For the closed porosity clear relationship neither with the sinter basicity nor with the share of concentrate was observed.

6. Porosity characterisation using mercury porosimetry and $3 \mathrm{D}$ tomography methods gives inherently incomparable results: the former characterises the pores by their intrusion diameter and the latter - by their equivalent spherical diameter.

7. After the non destructive tomography analysis the samples could be used for further research. This opens new possibilities to analyse the effect of the porosity in relation to the mechanical and physicochemical properties of the sinter. Study of the reducibility of the sinter samples, previously analysed using tomography method, confirms predominant influence of the open porosity on iron ore sinter reducibility. 


\section{References}

Bhagat, R. P.; Chattoraj, U. S. \& Sil, S. K. (2006): Porosity of Sinter and its relation with the sintering indices. Iron and Steel Institute of Japan International, Vol.46, 2006, pp. 1728-1730

Debrincat, D.; Loo, C. E. \& Hutchens, M. F. (2004). Effect of Iron Ore Particle Assimilation on Sinter Structure. Iron and Steel Institute of Japan International, Vol. 44, 2004, pp. 13081317

Ellis, B. G.; Loo, C. E. \& Witchard, D. (2007). Effect of ore properties on sinter bed permeability and strength. Ironmaking E Steelmaking, Vol. 34, 2006, pp.99-108.

Haga, T.; Nakano, M.; Kasama, S. \& Bergstrand, R. (2005). Effects of Metallic lron Bearing Resources on lron Ore Sintering. Proceedings of the $5^{\text {th }}$ European Coke and Ironmaking Congress. Stockholm, Sweden, June 2005, Vol.2, pp. 2:2-1-2:2-9.

Higuchi, K.; Naito, M.; Nakano, M. \& Takamoto, Y. (2004): Optimization of Chemical Composition and Microstructure of Iron Ore Sinter for Low-temperature Drip of Molten Iron with High Permeability. Iron and Steel Institute of Japan International, Vol. 44, (2004), pp. 2057-2066

Hosotani, Y.; Konno, N.; Yamaguchi, K.; Orimoro, T. \& Inazumi, T. (1996): Reduction properties of sinter with fine dispersed pores at high temperatures of $1273 \mathrm{~K}$ and above. Iron and Steel Institute of Japan International, Vol. 36, 1996, pp. 1439-1447

Hunt, G. BHP Billiton's iron ore business - current status and future outlook. Proceedings of the $7^{\text {th }}$ AJM Annual Global Iron Ore And Steel Forecast Conference, 23- February 2004, Brisbane, Australia

Katsman, V.; Shatokha, V. \& Emelyanov, V. (1986). Studies on partition of slag and metal during melting of sinter and pellets. Izvestiya VUZov. Chernaya Metallurgiya. № 9, 1986, pp. 11-13

Khosa, J. \& Manuel, J. (2007). Predicting Granulating Behaviour of Iron Ores Based on Size Distribution and Composition. Iron and Steel Institute of Japan International, Vol 47, 2007, pp. 965-972.

Kokubu, H.; Kodama, T.; Itaya, H. \& Oguchi, Y.(1986). Formation of pores in iron ore sinter Transactions of the Iron and Steel Institute of Japan International, Vol. 26, 1986, pp. 182185

Korotich, V. I. (1978). Fundamentals of the theory and technology of ironmaking burden preparation, Metallurgiya, Moscow, USSR.

Lide, D.R. (2004). CRC Handbook of Chemistry and Physics: A Ready-reference Book of Chemical and Physical Data, CRC Press, $2712 \mathrm{p}$.

Maire, E.; Buffière, J.-Y.; Salvo, L.; Blandin, J. J.; Ludwig, W. \& Létang, J. M.(2001): On the application of $\mathrm{x}$-ray microtomography in the field of materials science. Advanced Engineering Materials, Vol. 3, 2001, pp. 539 - 546.

Makkonen, H.T.; Heino, J.; Laitila, L.; Hiltunen, A.; Pöyliö, E. \& Härkki, J. (2002). Optimisation of steel plant recycling in Finland: dusts, scales and sludge. Resources, Conservation and Recycling. Vol. 35, 2002, pp.77-84

Manchinskiy, V. G. \& Shkodin, K. K. (1963). Overview on the development and modern state of the reduction processes kinetics. In: Modern Studies of the Blast Furnace Process, pp.153-166, Metallurgiya, Moscow, USSR 
Mou, J.-L.; Sun, Y-M.; Chen, Y-C.; Liao, C.W. \& Tarng, Y-S. (2007). Optical Line Scan Inspection System for Pseudo-particle Analysis. Iron and Steel Institute of Japan International, Vol.47, 2007, pp. 1780-1283

Naakano, M.; Yamakawa, K.; Hayakawa, N. \& Nagabuchi, M. (1998). Effects of Metallic lron Bearing Resources on lron Ore Sintering. Iron and Steel Institute of Japan International, Vol. 38, 1998, pp. 16-22

Shatokha, V.; Gogenko, O. \& Kripak, S. (2011). Utilising of the oiled rolling mills scale in iron ore sintering process. Resources, Conservation and Recycling, Vol.55, 2011, pp.435-440

Shatokha, V.; Korobeynikov, I.; Maire, E. \& Adrien, J. (2009). Application of 3D X-ray tomography to investigation of structure of sinter mixture granules. Ironmaking $\mathcal{E}$ Steelmaking, Vol. 36, 2009, pp.416-420.

Shatokha, V.; Korobeynikov, I.; Maire, E.; Gremillard, L. \& Adrien, J. (2010). Iron ore sinter porosity characterisation with application of 3D X-ray tomography. Ironmaking $\mathcal{E}$ Steelmaking, Vol. 37, 2010, pp.313-319

Slag atlas (1995). Ed. VDEh, 2nd Edition, Verlag Stahleisen GmbH, Dusseldorf, Germany

Yang, Y.-H. \& Standish, N., (1991). Mechanisms of Pore Formation in Iron Ore Sinter and Pellets. Iron and Steel Institute of Japan International, Vol. 31, 1991, pp. 468-477 http:/rsb.info.nih.gov/ij 


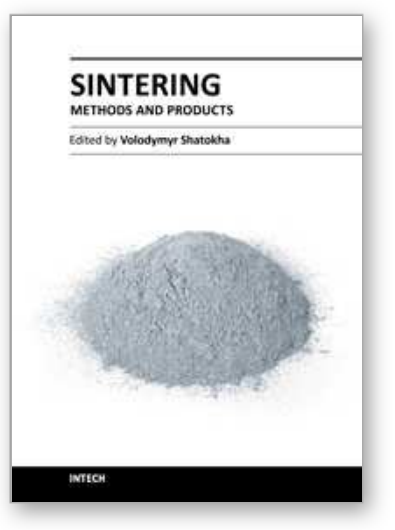

\author{
Sintering - Methods and Products \\ Edited by Dr. Volodymyr Shatokha
}

ISBN 978-953-51-0371-4

Hard cover, 316 pages

Publisher InTech

Published online 23, March, 2012

Published in print edition March, 2012

This book is addressed to a large and multidisciplinary audience of researchers and students dealing with or interested in sintering. Though commonly known as a method for production of objects from fines or powders, sintering is a very complex physicochemical phenomenon. It is complex because it involves a number of phenomena exhibiting themselves in various heterogeneous material systems, in a wide temperature range, and in different physical states. It is multidisciplinary research area because understanding of sintering requires a broad knowledge - from solid state physics and fluid dynamics to thermodynamics and kinetics of chemical reactions. Finally, sintering is not only a phenomenon. As a material processing method, sintering embraces the wide group of technologies used to obtain such different products as for example iron ore agglomerate and luminescent powders. As a matter of fact, this publication is a rare opportunity to connect the researchers involved in different domains of sintering in a single book.

\title{
How to reference
}

In order to correctly reference this scholarly work, feel free to copy and paste the following:

Volodymyr Shatokha, lurii Korobeynikov and Eric Maire (2012). On the Application of 3D X-Ray Microtomography for Studies in the Field of Iron Ore Sintering Technology, Sintering - Methods and Products, Dr. Volodymyr Shatokha (Ed.), ISBN: 978-953-51-0371-4, InTech, Available from:

http://www.intechopen.com/books/sintering-methods-and-products/on-the-application-of-3d-x-raymicrotomography-for-studies-in-the-field-of-iron-ore-sintering-techno

\section{INTECH}

open science | open minds

\section{InTech Europe}

University Campus STeP Ri

Slavka Krautzeka 83/A

51000 Rijeka, Croatia

Phone: +385 (51) 770447

Fax: +385 (51) 686166

www.intechopen.com

\section{InTech China}

Unit 405, Office Block, Hotel Equatorial Shanghai

No.65, Yan An Road (West), Shanghai, 200040, China

中国上海市延安西路65号上海国际贵都大饭店办公楼405单元

Phone: +86-21-62489820

Fax: $+86-21-62489821$ 
(C) 2012 The Author(s). Licensee IntechOpen. This is an open access article distributed under the terms of the Creative Commons Attribution 3.0 License, which permits unrestricted use, distribution, and reproduction in any medium, provided the original work is properly cited. 